\title{
Human GST loci as markers of evolutionary forces: GSTO1*E155del and GSTO1*E208K polymorphisms may be under natural selection induced by environmental arsenic
}

\author{
Renato Polimanti $i^{\mathrm{a}, \mathrm{b}}$, Sara Piacentini ${ }^{\mathrm{a}}$, Flavio De Angelis ${ }^{\mathrm{a}}$, Gian Franco De Stefano ${ }^{\mathrm{a}}$ and \\ Maria Fuciarelli ${ }^{\mathrm{a}, *}$ \\ a Department of Biology, University of Rome “Tor Vergata”, Rome, Italy \\ ${ }^{\mathrm{b}}$ Clinical Physiopathology Center, AFaR, “San Giovanni Calibita” Fatebenefratelli Hospital, Isola Tiberina, \\ Rome, Italy
}

\begin{abstract}
Over the last two decades, significant data has been accumulated linking Glutatione S-Transferases (GSTs) with the development of several diseases. Contemporary studies have demonstrated the impact of ethnicity on GST allele frequencies. The aim is to verify if the variability of GST genes reflects population demographic history or rather selective pressures. GST genes (GSTM1, GSTO1 GSTO2, GSTT1) were analysed in three Ecuadorian populations (Cayapas, $n=114$; Colorados, $n=104$; African-Ecuadorian, $n=77$ ) and compared with HapMap data. GST SNPs were determined using the PCR-RFLP method while GST null phenotype was determined using a Multiplex PCR.

The population relationship achieved using GSTM1 positive/null, GSTO1*A140D, GSTO2*N142D and GSTT1 positive/null are in agreement with the data obtained using neutral polymorphisms: Amerindians are close to Asian populations and AfricanEcuadorians to African populations. To what concerns GSTO1*del155 and GSTO1*K208 variants, allele frequencies never exceeded $10 \%$, showing no significant differences in the Ecuadorian groups and in worldwide populations.

The features of GSTO1*del155 and GSTO1*K208 variants and their association with arsenic biotransformation deficiency suggest the presence of a selection mechanism towards these loci. In particular, this hypothesis is strengthened by a possible linkage between these alleles and the susceptibility of arsenic-induced male infertility.
\end{abstract}

Keywords: Detoxification enzyme, Ecuador ethnic groups, natural selection, arsenic-induced male infertility

\section{Introduction}

Common functional allelic variants that affect gene expression or protein function have become increasingly popular markers in molecular genetics $[1,2]$. The Glutathione S-Transferases (GSTs) are an important enzymatic system in the cellular mechanism of detox-

* Corresponding author: Maria Fuciarelli, Department of Biology, University of Rome "Tor Vergata", Via della Ricerca Scientifica 1, 00133 Rome, Italy. Tel.: +39 0672594 346; E-mail: fuciarelli@ uniroma2.it. ification In general, GST-catalyzed reactions are considered detoxifying, thus protecting cellular macromolecules from damage caused by several environmental carcinogens $[3,4]$. Over the last two decades, a significant body of data has been accumulated linking mutant expression of GSTs with the development and expression of several multifactorial diseases [5-10]. In particular, many studies have investigated the relationship between GSTM1 and GSTT1 gene deletion polymorphisms and human health, while other GST polymorphisms (i.e. GSTO) are poorly understood and studied $[3,11,12]$. 
The GSTM1 locus has been mapped on chromosome 1p13.3. Three different alleles have been identified in the locus, including gene deletion (GSTM1*0) and two SNPs (GSTM1*A and GSTM1*B) that differ by $\mathrm{C}$ to $\mathrm{G}$ substitution at base position 534. The human GSTT1 gene is $8.1 \mathrm{~kb}$ in length and has been mapped on chromosome $22 \mathrm{q} 11.2$. Three variants have been identified: the GSTT $1 * 0$ allele caused by a gene deletion and the GSTT1*B allele that differs from GSTT1*A (wt) by an A to $\mathrm{C}$ mutation. Subjects with at least one functional GSTM1 or GSTT1 allele are grouped into the positive conjugator types and called GSTM1positive and GSTT1-positive, respectively. The deleted genotypes that lead to the inactive form of the enzymes are called "GSTM1-null" and "GSTT1-null". Although cytosolic GST enzymes occupy a key position in biological detoxification processes, frequencies of GSTM1 null and GSTT1 null phenotypes are relatively high in human populations with significant interethnic differences [13].

The GST Omega class (GSTO) contains two expressed genes GSTO1 and GSTO2 and a pseudo gene GSTO3p. GSTO1 and GSTO2 are 12.5 and $24.5 \mathrm{~kb}$, respectively, and lie $7.5 \mathrm{~kb}$ on chromosome 10q25.1. Previous studies have identified several polymorphisms in the GSTO genes [11,1416]. In particular, four polymorphisms in coding region have been identified in many ethnic groups (GSTO1*A140D, GSTO1*E155del, GSTO1*E208K and GSTO $2 *$ N142D) but their worldwide distribution is still far from completely understood [12].

Since detoxification enzymes are directly involved in interactions between living organisms and their environments, it is likely that the evolution of these proteins responds to and reflects changes in environment, including diet, climate, and lifestyle. Besides the phenomenon of random mutations, possible explanations for genetic change include adaptation to new environments in regard to diet or diseases and Williamson et al. [17] demonstrated that recent adaptations are strikingly pervasive in the human genome. Identification of loci that have been targets of natural selection and thus contribute to differences in fitness between individuals in a given population is an interesting approach in population genetics, and medical genetic markers may be useful for specialists in population genetics, population history, or disease history $[18,19]$.

As with other inhabitants of the Americas, the Ecuadorian population includes ethnically and genetically distinct groups besides native Ecuadorians, who make up nearly half the total population. Oth- er groups are the Ladinos, who are descended from the Spaniards who colonized Ecuador between the 16th and 19th centuries and intermixed to various extents with the autochthonous people, and a population of African ancestry descended from slaves imported mainly from western Africa during the colonial era. For their particular history, the existing communities of Ecuador offer an excellent context for exploring population dynamics and anthropological genetics [20]. In particular, this study furnishes data on GST polymorphisms in the Cayapa and Colorado Amerindians and in an African community of north western Ecuador. The aim is to verify if the genetic variability derived from the GSTM1 positive/null, GSTO1*A140D (rs4925), GSTO1*E155del (rs11509437), GSTO1*E208K (rs11509438), GSTO2* N142D (rs156697) and GSTT1 positive/null polymorphisms, which may be influenced by selection, present the same pattern found using other neutral polymorphisms. In fact, population demographic history affects patterns of variation at all loci in a genome in a similar manner, whereas natural selection acts upon specific loci [21]. At present, no studies have hypothesized the effect of natural selection on GST gene variability. The data are particularly surprising because GST enzymes plays a key role in defense against environmental stressors. Analysing the GST gene polymorphisms in the Ecuadorian populations and comparing our data with HapMap data, we try to verify if the variability of GST genes reflects population demographic history or rather selective pressures.

\section{Materials and methods}

Peripheral blood specimens were collected by one of us (G.F.D.S.) from a total of 295 unrelated and apparently healthy individuals of both sexes, who gave their informed consent, living along the Rio Cayapas River (Cayapas, $n=114$; African-Ecuadorians, $n=104$ ) and in the villages of Chihuilpe and Cóngoma (Colorados, $n=77$ ). The Cayapas (Chachi) and Colorados (Tsachilas) of Ecuador are Amerind language-family speakers who live in the tropical lowlands of the northwestern Pacific coast of Ecuador and are two of the last aboriginal groups in this area [22]. The AfricanEcuadorians, who account for a small percentage of the Ecuadorian population, live along the northern coast in the Esmeraldas province and in the northern highlands of the Chota River valley. The first clearly documented evidence of African settlements in Ecuador dates back 
to the middle of the 16th century, when a slave ship was reported to have run aground near the present town of Esmeraldas in 1553. Historical evidence shows that population intermixture has played a decisive role in the formation of the Ecuadorian people. Previous demographic and genetic studies, based on several markers, strongly supported this statement [23].

Each donor was asked to supply name, birthplace, language and ethnicity for 3 generations, in order to allow us to determine the extent of recent admixture. 5-10 $\mathrm{ml}$ of blood was drawn into sterile tubes containing acid citrate-dextrose anticoagulant, frozen in liquid nitrogen and then stored at $-80^{\circ} \mathrm{C}$ until DNA was extracted [24].

Genotyping of GSTM1 and GSTT1 genes was carried out by a multiplex PCR reaction [25], which permits discrimination of a null phenotype (GSTM1 or GSTT1 gene deletion in homozygous status) and a positive phenotype (homozygous wild type genotype or heterozygous genotype). The GSTO1*E155del polymorphism was determined using the confronting two-pair primer method [26]. This procedure permits discrimination simultaneously of the del155 allele and the E155 allele using two different pairs of primers. $10 \mathrm{ng}$ of DNA was amplified by PCR with a DNA thermal cycler (Peltier Thermal Cycler, MJ PTC-100, Celbio, Italy). The reaction mixture contained $1 \mathrm{X}$ buffer, $2 \mathrm{mM} \mathrm{Mg-}$ $\mathrm{Cl} 2,0.25 \mathrm{mM}$ of each primer, $250 \mathrm{mM}$ dNTPs and $1 \mathrm{U}$ of Taq polymerase (Fisher Molecular Biology, Trevose, PA, USA; MWG-Biotech AG, Ebersberg, Germany). The PCR protocol included an initial melting temperature of $94^{\circ} \mathrm{C}\left(4^{\prime}\right)$ followed by 27 cycles of amplification $\left(1^{\prime}\right.$ at $94^{\circ} \mathrm{C}, 30^{\prime \prime}$ at $57.3^{\circ} \mathrm{C}$ and $1^{\prime}$ at $\left.72^{\circ} \mathrm{C}\right)$. A final 7 ' extension step $\left(72^{\circ} \mathrm{C}\right)$ terminated the process. The GSTO1*A140D and GSTO2*N142D polymorphisms were determined using the PCR-RFLP method [27]: each PCR amplification was performed in $10 \mathrm{ng}$ genomic DNA, with the PCR mixtures consisting of a $1 \mathrm{X}$ PCR buffer, $2 \mathrm{mM} \mathrm{MgCl} 2,0.25 \mathrm{mM}$ of each primer, $250 \mathrm{mM}$ dNTPs and $1 \mathrm{U}$ of Taq polymerase (Fisher Molecular Biology; MWG-Biotech AG). After an initial denaturation at $94^{\circ} \mathrm{C}$ for $4^{\prime}$, amplification was performed by denaturation at $94^{\circ} \mathrm{C}$ for 1 ', annealing at $54.3^{\circ} \mathrm{C}$ or $58^{\circ} \mathrm{C}$ (respectively for GSTO 1 and GSTO2 polymorphisms) for 1 ' and extension at $72^{\circ} \mathrm{C}$ for 1 ' for 27 cycles, followed by a final extension at $72^{\circ} \mathrm{C}$ for 7 '. The PCR products were further digested with Cac8I and MboI restriction enzymes for GSTO1*A140D and GSTO2*N142D, respectively (New England Biolab, Hertfordshire, UK). To detect the GSTO1*E208K variant, an allele-specific PCR was carried out [28]: each
PCR amplification was performed in $10 \mathrm{ng}$ genomic DNA, using the PCR mixture consisting of a $1 \mathrm{X}$ PCR buffer, $2 \mathrm{mM} \mathrm{MgCl} 2,0.25 \mathrm{mM}$ of each primer, $50 \mathrm{mM}$ dNTPs and $1 \mathrm{U}$ of Taq polymerase (FisherMolecular Biology;MWG-Biotech AG). The reverse primer GSTO1*E208K-R was used together with the forward primer GSTO1*E208-F (wild-type) or the forward primer GSTO1*K208-F (mutant) in parallel reactions. After an initial denaturation at $94^{\circ} \mathrm{C}$ for $5^{\prime}$, amplification was performed by denaturation at $94^{\circ} \mathrm{C}$ for $1^{\prime}$, annealing at $53^{\circ} \mathrm{C}$ for $1^{\prime}$ and extension at $72^{\circ} \mathrm{C}$ for 1 ' for 35 cycles, followed by a final extension at $72^{\circ} \mathrm{C}$ for $10^{\prime}$. The genotypes were defined by different electrophoretic bands as described in our previous studies [9,12].

Statistical analysis was carried out using SPSS software (version 15.0 for Windows, Chicago, IL, USA). Allele frequencies were computed by the genotypecounting method. Hardy-Weinberg equilibrium was evaluated using the chi-square $\left(\mathrm{X}^{2}\right)$ test. Allelic differences among Ecuadorian populations were tested by means of the $\mathrm{X}^{2}$ test. GST allelic frequencies in worldwide populations were compared using correspondence analysis. Coefficients of pairwise LD (D') among GSTO gene polymorphisms were estimated using Haploview version 4.2 [29].

\section{Results}

Table 1 presents genotype and allele frequencies of GST gene polymorphisms. Genotype distribution was consistent with Hardy-Weinberg expectations for all loci and samples.

Comparing Amerindian populations, the greater differences in the GST gene pattern are the frequencies of the GSTM1 and GSTT1 null phenotypes $(p<0.05)$ whereas no main variations are present for GSTO gene polymorphisms. Conversely, the African-Ecuadorians show considerable difference in GSTO2*D142 allele frequency with respect to Amerindian populations ( $p<$ $0.05)$. No significant differences are highlighted in all Ecuadorian populations for GSTO1 gene polymorphisms.

To understand the observed GST gene variability in the analyzed populations, we matched our results with those reported in previous studies for different ethnic groups that are available on HapMap website (http://hapmap.ncbi.nlm.nih.gov). The comparisons between our findings and HapMap data show an interesting situation. Except for GSTO1*E155del 
Table 1

Allele frequencies and genotype distributions of GST gene polymorphisms in Cayapa and Colorado Amerindians and in a Afro-Ecuadorian population sample

\begin{tabular}{|c|c|c|c|}
\hline & $\begin{array}{l}\text { Cayapas } \\
n=114\end{array}$ & $\begin{array}{c}\text { Colorados } \\
n=77\end{array}$ & $\begin{array}{c}\text { African-Ecuadorians } \\
n=104\end{array}$ \\
\hline \multicolumn{4}{|l|}{ GSTM1 } \\
\hline Positive (\%) & $92(81)$ & $36(47)$ & $68(65)$ \\
\hline Null (\%) & $22(19)$ & $41(53)$ & $36(35)$ \\
\hline \multicolumn{4}{|c|}{ GSTO1*A140D (rs4925) } \\
\hline$A 140$ & 0.974 & 0.909 & 0.904 \\
\hline$D 140$ & $0.026 \pm 0.011$ & $0.091 \pm 0.023$ & $0.096 \pm 0.020$ \\
\hline A140/A140 (\%) & $108(95)$ & $63(82)$ & $85(82)$ \\
\hline$A 140 / D 140(\%)$ & $6(5)$ & $14(18)$ & $18(17)$ \\
\hline$D 140 / D 140(\%)$ & $0(0)$ & $0(0)$ & $1(1)$ \\
\hline \multicolumn{4}{|c|}{ GSTO1*E155del (rs11509437) } \\
\hline E155 & 0.930 & 0.942 & 0.961 \\
\hline del155 & $0.070 \pm 0.017$ & $0.058 \pm 0.019$ & $0.039 \pm 0.013$ \\
\hline E155/E155 (\%) & $98(86)$ & $68(88)$ & $96(92)$ \\
\hline E155/del155 (\%) & $16(14)$ & $9(12)$ & $8(8)$ \\
\hline \multicolumn{4}{|c|}{ GSTO1*E208K (rs11509438) } \\
\hline$E 208$ & 0.917 & 0.948 & 0.952 \\
\hline$K 208$ & $0.083 \pm 0.018$ & $0.052 \pm 0.017$ & $0.048 \pm 0.015$ \\
\hline E208/E208 (\%) & $95(83)$ & $69(90)$ & $94(90)$ \\
\hline E208/K208 (\%) & $19(17)$ & $8(10)$ & $10(10)$ \\
\hline \multicolumn{4}{|c|}{ GSTO2*N142D (rs156697) } \\
\hline$N 142$ & 0.925 & 0.903 & $0.433 \pm 0.034$ \\
\hline$D 142$ & $0.075 \pm 0.017$ & $0.097 \pm 0.024$ & 0.567 \\
\hline N142/N142(\%) & $98(86)$ & $63(82)$ & $14(13)$ \\
\hline N142/D142(\%) & $15(13)$ & $13(17)$ & $62(60)$ \\
\hline D142/D142 (\%) & $1(1)$ & $1(1)$ & $28(27)$ \\
\hline \multicolumn{4}{|l|}{ GSTT1 } \\
\hline Positive (\%) & $111(97)$ & $67(87)$ & $82(79)$ \\
\hline $\operatorname{Null}(\%)$ & $3(3)$ & $10(13)$ & $22(21)$ \\
\hline
\end{tabular}

and GSTO1*E208K, the GST allele frequencies show significant inter-population differences, according to their geographical origin.

A different range of GSTM1 null frequencies was observed for populations of African (20 to 32\%), Asian (32 to $50 \%$ ) and European origin (55 to 59\%). In African-Ecuadorians and Colorados, the GSTM1 null frequency fits with the frequencies found in the Africans and Asians, respectively. Cayapas show a GSTM1 null frequency lower than those found in Asian origin populations. The GSTO1*D140 allele frequencies observed in the African-Ecuadorians are similar to African frequencies, ranging from $4 \%$ to 21\%, whereas Cayapas and Colorado Amerindians show GSTO $1 *$ D 140 allele frequencies lower than those found in Asians, ranging from $15 \%$ to $20 \%$. In the European origin population, the GSTO1*D140 allele shows frequencies higher than those observed in Africans and Asians, ranging from $34 \%$ to $37 \%$. GSTO1*E155del and GSTO1*E208K mutation frequencies never exceeded $10 \%$, with no significant differences among worldwide populations. For GSTO2*N142D, similar allele frequencies were observed in Europeans and Asians: in the Asian populations, the D142 allele frequency (22 to $33 \%$ ) was slightly lower than in the European populations (38 to $39 \%$ ). By contrast, the D142 allele frequency of the African origin population was higher, ranging from $67 \%$ to $86 \%$. In Cayapa and Colorados, the D142 allele frequencies are lower than those found in Asians, whereas the African-Ecuadorians fit within the range of values found in African populations. Regarding to the GSTT1 null phenotype, Cayapa and Colorado Amerindians show frequencies lower than those found in the Asian population (19 to $41 \%$ ), while African-Ecuadorians fall within the range of variability observed in African populations (15 to 35\%).

Correspondence analysis performed on GST allelic frequencies shows diversity among worldwide populations and distinguishes three main clusters: a cluster including European samples, another cluster consisting of Asian populations and a third cluster comprising African populations (Fig. 1). In accordance with their ancestry, Cayapas and Colorados are included in the "Asian" cluster and African-Ecuadorians in the "African" cluster. 


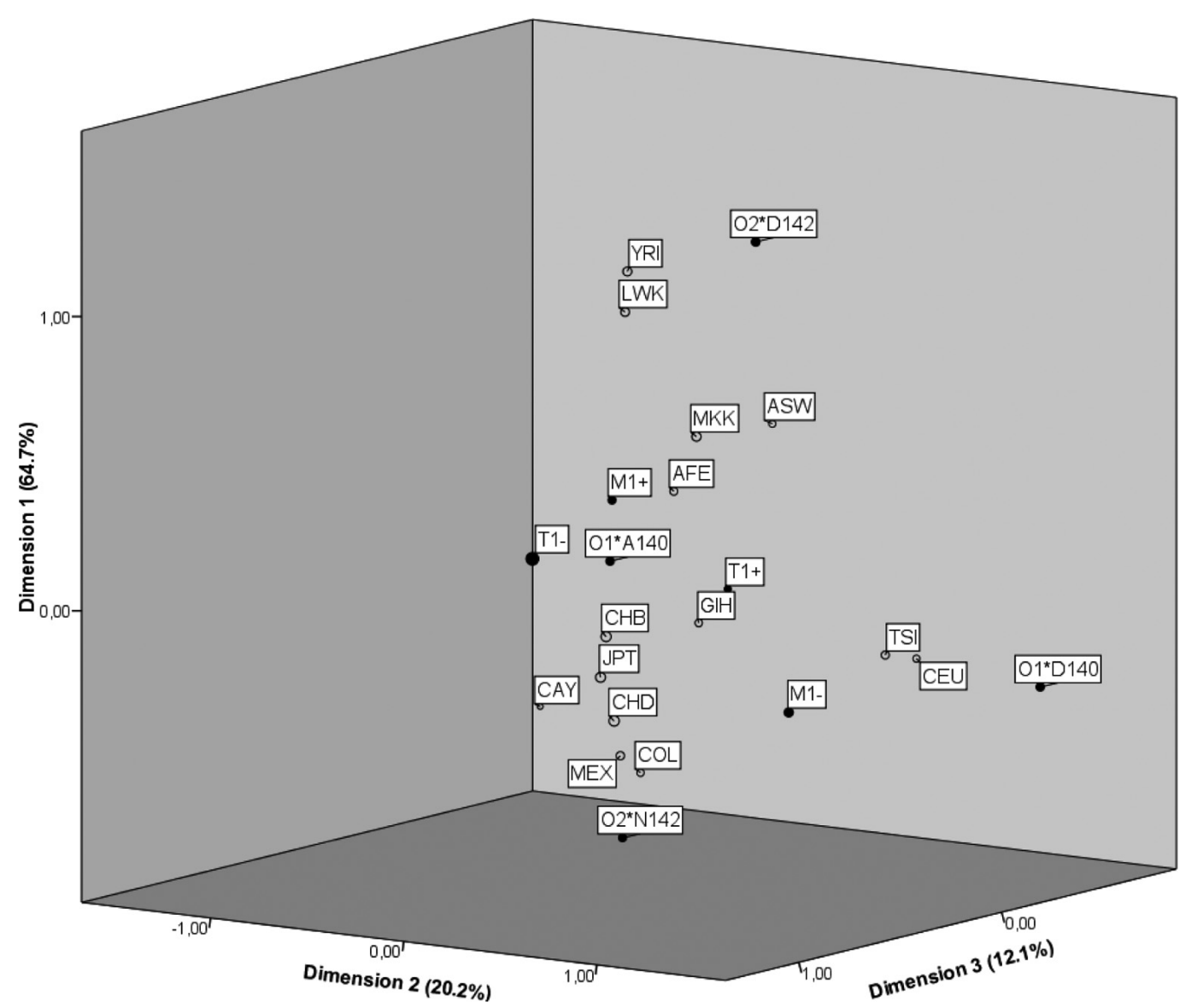

Fig. 1. Correspondence analysis by GST allelic frequencies (full circles) in the Ecuadorian ethnic groups and the HapMap populations (empty circles) (available on http://hapmap.ncbi.nlm.nih.gov). [AFE: African-Ecuadorians; ASW: African ancestry in Southwest USA; CAY: Cayapas; $C E U$ : Utah residents with Northern and Western European ancestry from the CEPH collection; $C H B$ : Han Chinese in Beijing, China; $C H D$ : Chinese in Metropolitan Denver, Colorado; COL: Colorados; GIH: Gujarati Indians in Houston, Texas; JPT: Japanese in Tokyo, Japan; LWK: Luhya in Webuye, Kenya; MEX: Mexican ancestry in Los Angeles, California; MKK: Maasai in Kinyawa, Kenya; TSI: Tuscans in Italy; YRI: Yoruba in Ibadan, Nigeria].

The GSTO1*del155 and GSTO1*K208 alleles show very low frequencies in different ethnic groups and people with both variants were identified. Sixteen Cayapa individuals present the Glu155 deletion and fifteen are also heterozygous for the Glu208Lys change. Eight of nine Colorados with the Glu155del present the double variant genotype and seven of ten African-Ecuadorians with both variant alleles were identified. In order to investigate LD among all GSTO gene polymorphisms, plots were constructed for the analyzed populations (Fig. 2). In all groups, E155del and E208K polymorphisms are in high LD (D' value 0.86 to 1.00 ). LD is comparatively much lower between the other genetic polymorphism pairs for all three populations. As previously hypothesized for other ethnic groups [12,16,28, 30], our result may confirm the linkage in the GSTO1 gene with E155 deletion and E208K substitution in these Ecuadorian populations.

\section{Discussion}

The GSTs are key regulators of drug and toxin clearance. Alleles of GST genes have been known for more than a decade and several disease association studies have been conducted on these polymorphisms. At present few researches have investigated the role of selection on GST genes and/or the potential role of GST gene polymorphism in the process of adaptation.

Our research determined the genetic variability of GSTs in three Ecuadorian populations to test if the evolution of these xenobiotic-metabolism genes reflects population demographic history or rather selec- 


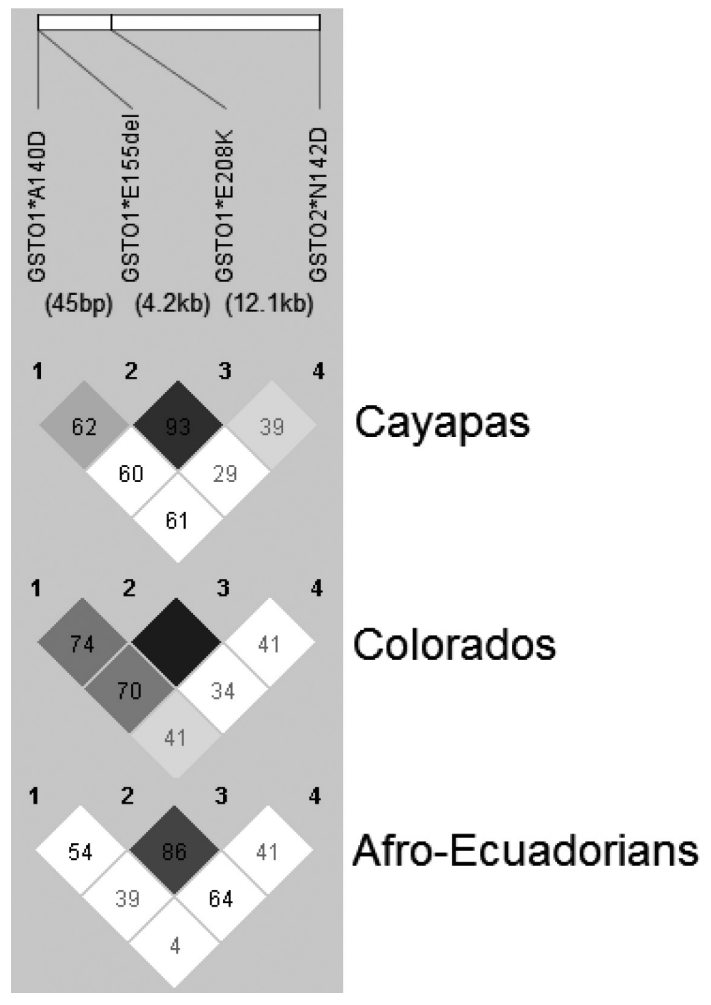

Fig. 2. Pairwise LDs are shown, calculated between the GSTO gene polymorphisms in the three populations of Ecuador. The top panel depicts the location of the polymorphisms in the GSTO cluster. The intensity of the box shading is proportional to the strength of the LD (D'/LOD) for the marker pair, which is also indicated as a percentage within each box. For boxes without any number, $D^{\prime}=1$.

tive pressures. For this reason, we analyzed the interethnic differences in these genetic markers in populations of anthropological interest using the HapMap populations as references.

The comparison between the present findings and HapMap data strengthen an interesting hypothesis: for almost all GST gene polymorphisms analyzed in this study (GSTM1 positive/null, GSTO1*A140D, GSTO2*N142D and GSTT1 positive/null), differences among human populations are probably due to their ethnogenesis. In fact, the population relationships obtained using these genetic markers are in agreement with the result obtained by neutral polymorphisms: Cayapa and Colorado Amerindians are close to Asian populations and African-Ecuadorians are close to African populations, in accordance with their origins. Therefore, it is plausible that in these GST gene polymorphisms differences could be due to a different demographic history and/or to a founder effects. This hypothesis could be confirmed by observing different frequencies of GSTM1 and GSTT1 null phenotypes between Cayapas and Colorados. Indeed, this result agrees with previous studies that investigated GSTT1 and GSTM1 gene polymorphisms in worldwide populations [13,31]. Genetic diversities among Amerindians are observed for the frequencies of GSTM1 and GSTT1 gene deletion polymorphisms, probably due to the particular history of these populations. Regarding GSTO2*N142D, African-Ecuadorians differ significantly from Cayapas and Colorados, as do African origin from Asian origin populations, while for GSTO1*A140D, the three analyzed ethnic groups do not show significant differences like the African and Asian origin populations.

A different conclusion can be reached for GSTO1* E155del and GSTO1*E208K polymorphisms: the mutation frequencies are low, with no significant interethnic differences and LD is high both in previous population studies and in the studied communities of Ecuador. These features demonstrated that demographic population history does not affect patterns of variation in these polymorphisms, instead natural selection may have acted upon these loci.

Considering the effects of these allelic variants on the GSTO1-1 enzyme, deletion of E155 in exon 4 and E208K substitution in exon 6 are thought to be related to significant changes in GSTO1-1 activities with an important decrease in enzyme stability $[11,15$, 16,32]. In vitro, GSTO1-1 has been shown to catalyse the reduction steps in the arsenic biotransformation pathway: dimethylarsinic acid $\left(\mathrm{DMA}^{V}\right)$ reductase and monomethylarsonic acid $\left(\mathrm{MMA}^{V}\right)$ reductase [14]. Several studies have highlighted that GSTO1*del155 and GSTO1*K208 variants are related to deficiencies in arsenic biotransformation process [5,14,33], but some authors not confirm this association [28,30]. The contrasting results might be due to the hypothesis that each step of the biotransformation of inorganic arsenic has an alternative enzyme to biotransform the arsenic substrate [34]. However, Chowdhury and colleagues [34] have observed a large decrease in $\mathrm{MMA}^{V}$ reducing activity in some tissues (urinary, bladder, testes, brain, liver, skin, and lungs) of the GSTO1 Knockout mice. Therefore, it is possible to suppose that GSTO1*del155 and GSTO1*K208 variants are involved in deficiencies of the arsenic bio-transformation process in some human tissues.

The role of the arsenic biotransformation process may significantly enhance the cytotoxic and carcinogenic risk of arsenic exposure [35]. Exposure to arsenic in the workplace and in the environment has been associated with numerous adverse health effects. Acute 
exposures to high doses of arsenic often produce gastrointestinal disturbances, central and peripheral neurotoxicity, bone-marrow suppression, and hepatic toxicity [36]. Chronic exposure to lower doses of arsenic resulted in skin lesions, peripheral neuropathy, cardiovascular disease, several types of cancer and reproductive toxicity [36-38]. Arsenic is an ubiquitous metalloid in the crust of the earth, and human exposure to inorganic arsenic is mainly through ingestion of drinking water contaminated with naturally occurring arsenic [39]. Arsenic occurrence and mobilization take place through a combination of natural processes (e.g., weathering reactions, biological activity, volcanic emissions, etc.) [40]. In addition, Arsenic releases from anthropogenic activities (nonferrous metal mining and smelting, pesticide and herbicide use, wood preserving, coal combustion, and waste incineration) may be an important source of environmental contamination [41]. To date there are no data on arsenic exposure in the Ecuadorian environment but several studies have highlighted that the high volcanic mountains of the Andes are a source of naturally occurring arsenic for all countries of Latin America [40]. Since arsenic is found naturally in the environment, all individuals are exposed to some arsenic by eating food, drinking water, or breathing air [36]. Therefore it is plausible hypothesized that all human populations are exposed to environmental arsenic.

The worldwide distribution of GSTO1*E155del and GSTO1*E208K and their involvement in arsenic biotransformation suggest that these two genetic variants could be associated with negative traits linked to environmental arsenic. We know that natural selection on genetic traits occurs when the variation in traits is correlated with the variation in fitness. Evidence for the adaptive status of a trait would require evidence of differential fertility or mortality dependent on a particular genetic difference [42]. The adverse health effects induced by environmental arsenic are associated with serious pathological conditions. Among these, arsenic-induced male infertility could represent the strongest negative selective pressure associated with GSTO1*K208 and GSTO1*del155 variants. Different studies have highlighted that arsenic is associated with male infertility even at environmental exposure levels [43-45].

At the present, the potential effects of genetic polymorphisms that modulate the arsenic biotransformation, such as GSTO1 polymorphisms, on reproductive outcomes have not been investigated. Nevertheless, Wirth and Mijal [44] have already hypothe- sized that GSTO1 could be a marker of susceptibility for reproductive toxicity induced by environmental arsenic. This hypothesis could explain the presence of low mutation frequencies for GSTO1*E155del and GSTO1*E208K polymorphisms in different ethnic groups: the presence of a relationship between these polymorphisms and human reproduction outcomes could justify the existence of natural selection mechanisms on the GSTO1 locus. Moreover, the high LD among E155del and E208K polymorphisms may suggest that these genetic markers have a combined effect on the GSTO1-1 enzyme, but to date no studies have investigated this hypothesis.

In conclusion, this study provides significant information on the variability of GST gene polymorphisms in worldwide populations. As previously hypothesized, different patterns are present in African, Asian and European populations for almost all GST polymorphisms analyzed, proving that population demographic history affects the genetic variability of these loci. However, the association between these genes and the susceptibility to certain diseases could explain the prevalence and incidence variability of multifactorial diseases in human populations. Further studies on the population relationships and the genetic variability of medical markers, such as GSTs, could explain the relationship between ethnicity and disease risk. The present data on GSTO1*E155del and GSTO1*E208K, however, demonstrated that population demographic history did not affect the genetic variability of these markers, highlighting the hypothesis of the presence of selective mechanisms in these GST loci. This statement is particularly interesting because of the lack of studies suggesting the action of natural selection on the GST genetic diversity among human populations.

\section{Acknowledgements}

This research was supported by MIUR Grant, (COFIN 2006, 2006053308) to GFDS and by RSA Grant 2009 (University of Rome "Tor Vergata") to MF. RP thanks Prof. Dario Manfellotto for his valuable support. The subjects of the investigation were adequately informed about the aims of the study and gave their written consent. Human studies have been approved by the appropriate ethics committee and have therefore been performed in accordance with the ethical standards as laid down by law. The authors declare that they have no conflict of interest. 


\section{References}

[1] M.I. McCarthy, G.R. Abecasis, L.R. Cardon, D.B. Goldstein, J. Little, J.P. Ioannidis and J.N. Hirschhorn, Genome-wide association studies for complex traits: consensus, uncertainty and challenges, Nat Rev Genet 9 (2008), 356-369.

[2] K.A. Frazer, S.S. Murray, N.J. Schork and E.J. Topol, Human genetic variation and its contribution to complex traits, Nat Rev Genet 10 (2009), 241-251.

[3] H.M. Bolt and R. Thier, Relevance of the deletion polymorphisms of the glutathione S-transferases GSTT1 and GSTM1 in pharmacology and toxicology, Curr Drug Metab 7 (2006), 613-628.

[4] M. Fuciarelli, A. Caccuri, M. De Francesca, F. Ferazzoli, S. Piacentini and F. Porreca, Modulation of the GSTT1 activity by the GSTM1 phenotype in a sample of Italian farm-workers, Arch Toxicol 83 (2009), 115-120.

[5] E.M. Schmuck, P.G. Board, A.K. Whitbread, N. Tetlow, J.A. Cavanaugh, A.C. Blackburn and A. Masoumi, Characterization of the monomethylarsonate reductase and dehydroascorbate reductase activities of Omega class glutathione transferase variants: implications for arsenic metabolism and the age-at-onset of Alzheimer's and Parkinson's diseases, Pharmacogenet Genomics 15 (2005), 493-501.

[6] T.H. Harju, M.J. Peltoniemi, P.H. Rytilä, Y. Soini, K.M. Salmenkivi, PG Board, L.W. Ruddock and V.L. Kinnula, Glutathione S-transferase omega in the lung and sputum supernatants of COPD patients, Respir Res 8 (2007), 48.

[7] T. Hashimoto, K. Hashimoto, R. Miyatake, D. Matsuzawa, Y Sekine, T. Inada, N. Ozaki, N. Iwata, M. Harano, T. Komiyama, M. Yamada, I. Sora, H. Ujike and M. Iyo, Association study between polymorphisms in glutathione-related genes and methamphetamine use disorder in a Japanese population, Am J Med Genet B Neuropsychiatr Genet 147B (2008), 10401046.

[8] G. Di Pietro, L.A. Magno and F. Rios-Santos, Glutathione S-transferases: an overview in cancer research, Expert Opin Drug Metab Toxicol 6 (2010), 153-170.

[9] S. Piacentini, R. Polimanti, B. Moscatelli, M.A. Re, R. Fuciarelli, D. Manfellotto and M. Fuciarelli, Glutathione Stransferase gene polymorphisms and air pollution as interactive risk factors for asthma in a multicentre Italian field study: A preliminary study, Ann Hum Biol 37 (2010), 427-439.

[10] R. Polimanti, S. Piacentini, B. Moscatelli, L. Pellicciotti, D. Manfellotto and M. Fuciarelli, GSTA1, GSTO1 and GSTO2 gene polymorphisms in Italian asthma patients, Clin Exp Pharmacol Physiol 37 (2010), 870-872.

[11] A.K. Whitbread, A. Masoumi, N. Tetlow, E. Schmuck, M. Coggan and P.G. Board, Characterization of the omega class of glutathione transferases, Methods Enzymol 401 (2005), 7899.

[12] R. Polimanti, S. Piacentini, F. Porreca and M. Fuciarelli, Glutathione S-transferase Omega class (GSTO) polymorphisms in a sample from Rome (Central Italy), Ann Hum Biol 37 (2010), 585-592.

[13] S. Piacentini, R. Polimanti, F. Porreca, C. Martínez-Labarga, G.F. De Stefano and M. Fuciarelli, GSTT1 and GSTM1 gene polymorphisms in European and African populations, Mol Biol Rep 38 (2010), 1225-3020.

[14] L.L Marnell, G.G Garcia-Vargas, U.K. Chowdhury, R.A. Zakharyan, B. Walsh, M.D. Avram, M.J. Kopplin, M.E. Cebrián, E.K. Silbergeld and H.V. Aposhian, Polymorphisms in the human monomethylarsonic acid (MMA V) reductase/hGSTO1 gene and changes in urinary arsenic profiles, Chem Res Toxicol 16 (2003), 1507-1513.

[15] L. Yu, K. Kalla, E. Guthrie, A. Vidrine and W.T. Klimecki, Genetic variation in genes associated with arsenic metabolism: glutathione S-transferase omega 1-1 and purine nucleoside phosphorylase polymorphisms in European and indigenous Americans, Environ Health Perspect 111 (2003), 1421-1427.

[16] B. Mukherjee, O.E. Salavaggione, L.L. Pelleymounter, I. Moon, B.W. Eckloff, D.J. Schaid, E.D. Wieben and R.M. Weinshilboum, Glutathione S-transferase omega 1 and omega 2 pharmacogenomics, Drug Metab Dispos 34 (2006), 12371246.

[17] S.H. Williamson, M.J. Hubisz, A.G. Clark, B.A. Payseur, C.D. Bustamante and R. Nielsen, Localizing recent adaptive evolution in the human genome, PLoS Genet 3 (2007), e90.

[18] S.A. Tishkoff and B.C. Verrelli. Patterns of human genetic diversity: Implications for human evolutionary history and disease, Annu Rev Genomics Hum Genet 4 (2003), 293-340.

[19] F. Bauduer, A. Degioanni and O. Dutour, Medical genetic polymorphisms as markers of evolutionary forces within the human genome: hypotheses focusing on natural selection in the Basque population, Hum Biol 81 (2009), 23-42.

[20] F. González-Andrade, D. Sánchez, J. González-Solórzano, S. Gascón and B. Martínez-Jarreta, Sex-specific genetic admixture of Mestizos, Amerindian Kichwas, and AfricanEcuadorans from Ecuador, Hum Biol 79 (2007), 51-77.

[21] J.M Akey, M.A. Eberle, M.J Rieder, C.S. Carlson, M.D. Shriver, D.A. Nickerson and L. Kruglyak, Population history and natural selection shape patterns of genetic variation in 132 genes, PLoS Biol 2 (2004), e286.

[22] C. Babalini, T. Tarsi, C. Martínez-Labarga, G. Scano, G. Pepe, G.F. De Stefano and O. Rickards, COL1A2 (type I collagen) polymorphisms in the Colorado Indians of Ecuador, Ann Hum Biol 32 (2005), 666-678.

[23] O. Rickards, C. Martínez-Labarga, E. Trucchi, F. Renzi, R. Casalotti, C. Babalini, G. Biondi, G. Pepe and D, Stefano, Restriction fragment length polymorphisms of type I collagen locus 2 (COL1A2) in two communities of African ancestry and other mixed populations of northwestern Ecuador, Hum Biol 77 (2005), 115-123.

[24] S.A. Miller, D.D. Dykes and H.F. Polesky, A simple salting out procedure for extracting DNA from human nucleated cells, Nucleic Acids Res 16 (1988), 1215.

[25] S.Z. Abdel-Rahman, R.A. El-Zein, W.A. Anwar and W.W. $\mathrm{Au}, \mathrm{A}$ multiplex PCR procedure for polymorphic analysis of GSTM1 and GSTT1 genes in population studies, Cancer Lett 107 (1996), 229-233.

[26] J. Fujihara, T. Kunito and H. Takeshita, Frequency of two human glutathione-S-transferase omega-1 polymorphisms (E155 deletion and E208K) in Ovambo and Japanese populations using the PCR-based genotyping method, Clin Chem Lab Med 45 (2007), 621-624.

[27] H. Takeshita, J. Fujihara, H. Takastuka, T. Agusa, T. Yasuda and T. Kunito, Diversity of glutathione S-transferase omega 1 (A140D) and 2 (N142D) gene polymorphisms in worldwide populations, Clin Exp Pharmacol Physiol 36 (2009), 283-286.

[28] L. Paiva, R. Marcos, A. Creus, M. Coggan, A.J. Oakley and P.G. Board, Polymorphism of glutathione transferase Omega 1 in a population exposed to a high environmental arsenic burden, Pharmacogenet Genomics 18 (2008), 1-10.

[29] J.C. Barrett, B. Fry, J. Maller and M.J. Daly, Haploview: analysis and visualization of LD and haplotype maps, Bioinformatics 21 (2005), 263-265. 
[30] E. Schmuck, J. Cappello, M. Coggan, J. Brew, J.A. Cavanaugh, A.C. Blackburn, R.T. Baker, H.J. Eyre, G.R. Sutherland and P.G. Board, Deletion of Glu155 causes a deficiency of glutathione transferase Omega 1-1 but does not alter sensitivity to arsenic trioxide and other cytotoxic drugs, Int J Biochem Cell Biol 40 (2008), 2553-2559.

[31] P.A. Gaspar, M.H. Hutz, F.M. Salzano, K. Hill, A.M. Hurtado, M.L. Petzl-Erler, L.T. Tsuneto and T.A. Weimer, Polymorphisms of CYP1a1, CYP2e1, GSTM1, GSTT1, and TP53 genes in Amerindians, Am J Phys Anthropol 119 (2002), 249256.

[32] H. Zhou, J. Brock, M.G. Casarotto, A.J. Oakley and P.G. Board, Novel folding and stability defects cause a deficiency of human glutathione transferase omega 1, J Biol Chem 286 (2011), 4271-4279.

[33] T. Agusa, H. Iwata, J. Fujihara, T. Kunito, H. Takeshita, T.B. Minh, T.P. Trang, P.H. Viet and S. Tanabe, Genetic polymorphisms in glutathione S-transferase (GST) superfamily and arsenic metabolism in residents of the Red River Delta, Vietnam, Toxicol Appl Pharmacol 242 (2010), 352-362.

[34] U.K. Chowdhury, R.A. Zakharyan, A. Hernandez, M.D. Avram, M.J. Kopplin and H.V. Aposhian, Glutathione-Stransferase-omega $[\mathrm{MMA}(\mathrm{V})$ reductase] knockout mice: enzyme and arsenic species concentrations in tissues after arsenate administration, Toxicol Appl Pharmacol 216 (2006), 446-457.

[35] A. Hernandez and R. Marcos, Genetic variations associated with interindividual sensitivity in the response to arsenic exposure, Pharmacogenomics 9 (2008), 1113-1132.

[36] Agency for Toxic Substances and Disease Registry. Toxicological profile for arsenic. Agency for Toxic Substances and Disease Registry. Atlanta, GA. (2007). http://www.atsdr. cdc.gov/toxprofiles/tp2.pdf. (accessed October 1, 2010)

[37] M.F. Hughes, Arsenic toxicity and potential mechanisms of action, Toxicol Lett 133 (2002), 1-16.

[38] A. Schoen, B. Beck, R. Sharma and E. Dubè, Arsenic toxicity at low doses: epidemiological and mode of action considerations, Toxicology and Applied Pharmacology 198 (2004), 253-267.

[39] K.L. Caldwell, R.L. Jones, C.P. Verdon, J.M. Jarrett, S.P. Caudill and J.D. Osterloh, Levels of urinary total and speciated arsenic in the US population: National Health and Nutrition Examination Survey 2003-2004, J Expo Sci Environ Epidemiol 19 (2009), 59-68.

[40] M.I. Litter, M.E. Morgada and J. Bundschuh, Possible treatments for arsenic removal in Latin American waters for human consumption, Environ Pollut 158 (2010), 1105-1118.

[41] K. Orloff, K. Mistry and S. Metcalf, Biomonitoring for environmental exposures to arsenic, J Toxicol Environ Health B Crit Rev 12 (2009), 509-524.

[42] E.E. Harris and D. Meyer, The molecular signature of selection underlying human adaptations, Am J Phys Anthropol Suppl $\mathbf{4 3}$ (2010), 89-130.

[43] J.D. Meeker, M.G. Rossano, B. Protas, M.P. Diamond, E. Puscheck, D. Daly, N. Paneth and J.J. Wirth, Cadmium, lead, and other metals in relation to semen quality: human evidence for molybdenum as a male reproductive toxicant, Environ Health Perspect 116 (2008), 1473-1479.

[44] J.J. Wirth and R.S. Mijal, Adverse effects of low level heavy metal exposure on male reproductive function, Syst Biol Reprod Med 56 (2010), 147-167.

[45] A.E. Rosenblatt and K.L. Burnstein, Inhibition of androgen receptor transcriptional activity as a novel mechanism of action of arsenic, Mol Endocrinol 23 (2009), 412-421. 


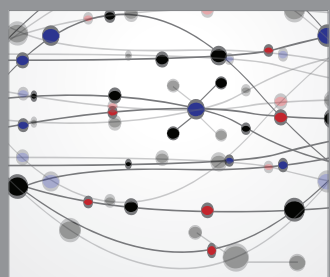

The Scientific World Journal
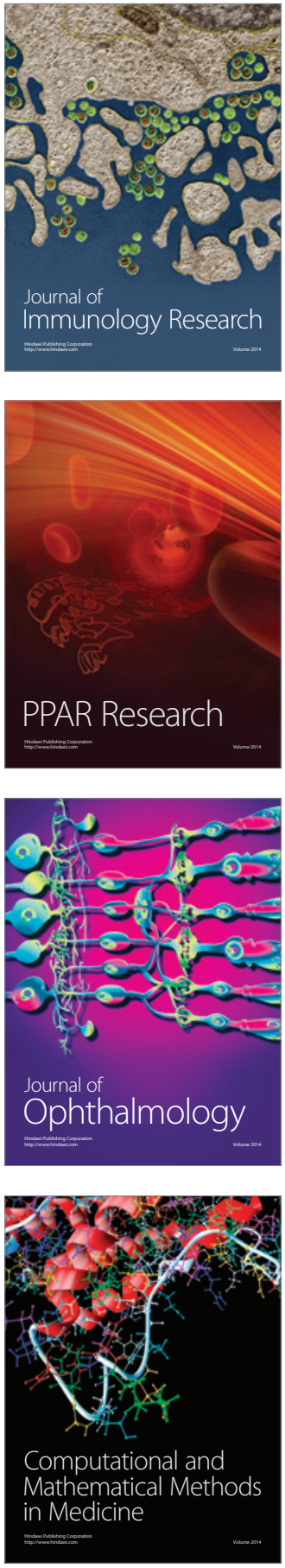

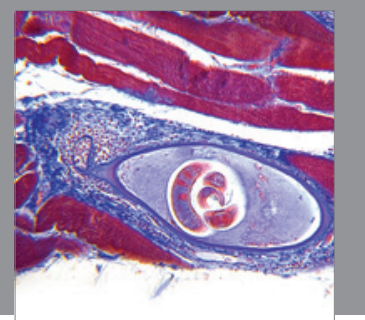

Gastroenterology

Research and Practice
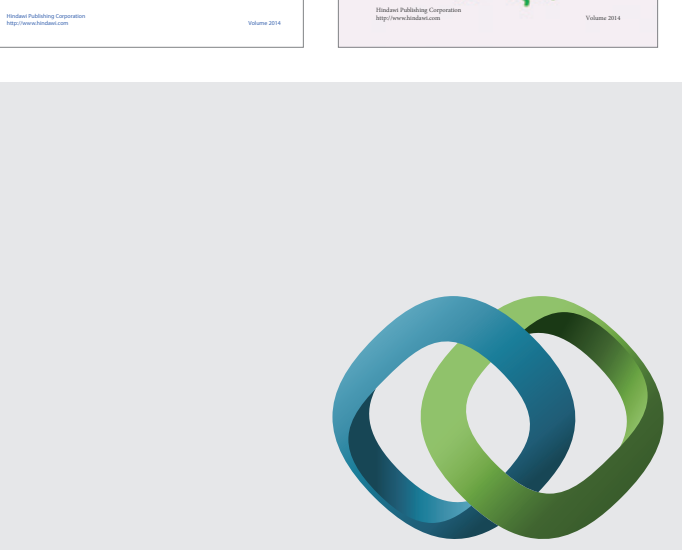

\section{Hindawi}

Submit your manuscripts at

http://www.hindawi.com
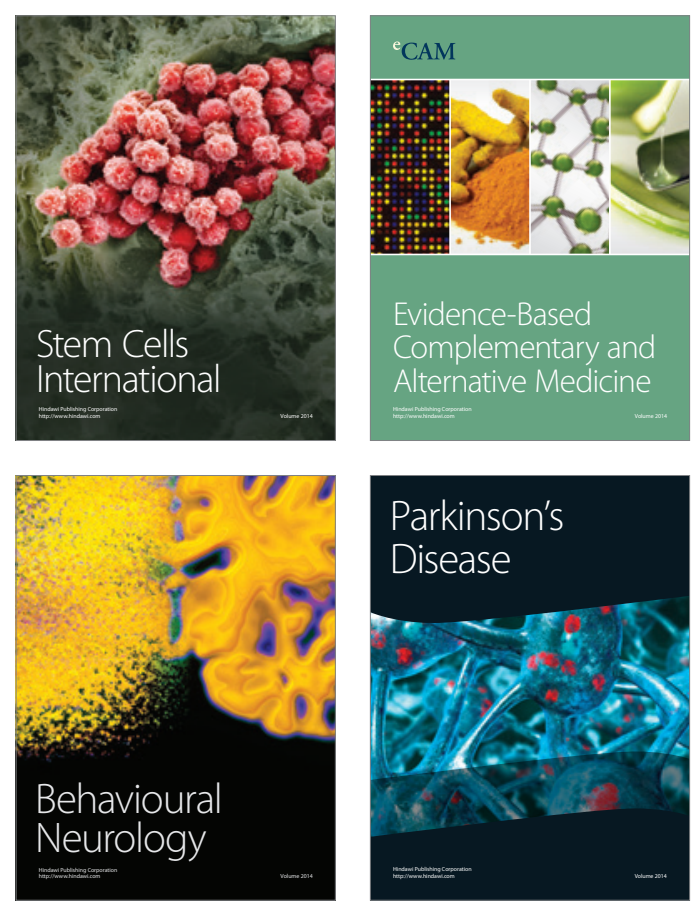

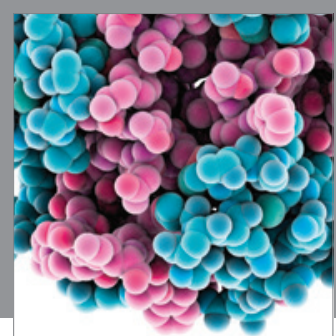

Journal of
Diabetes Research

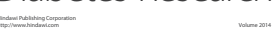

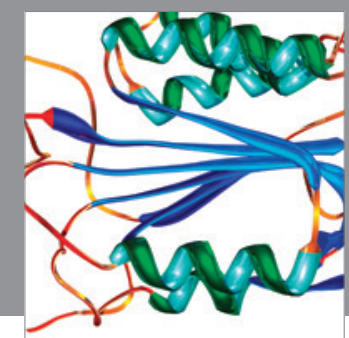

Disease Markers
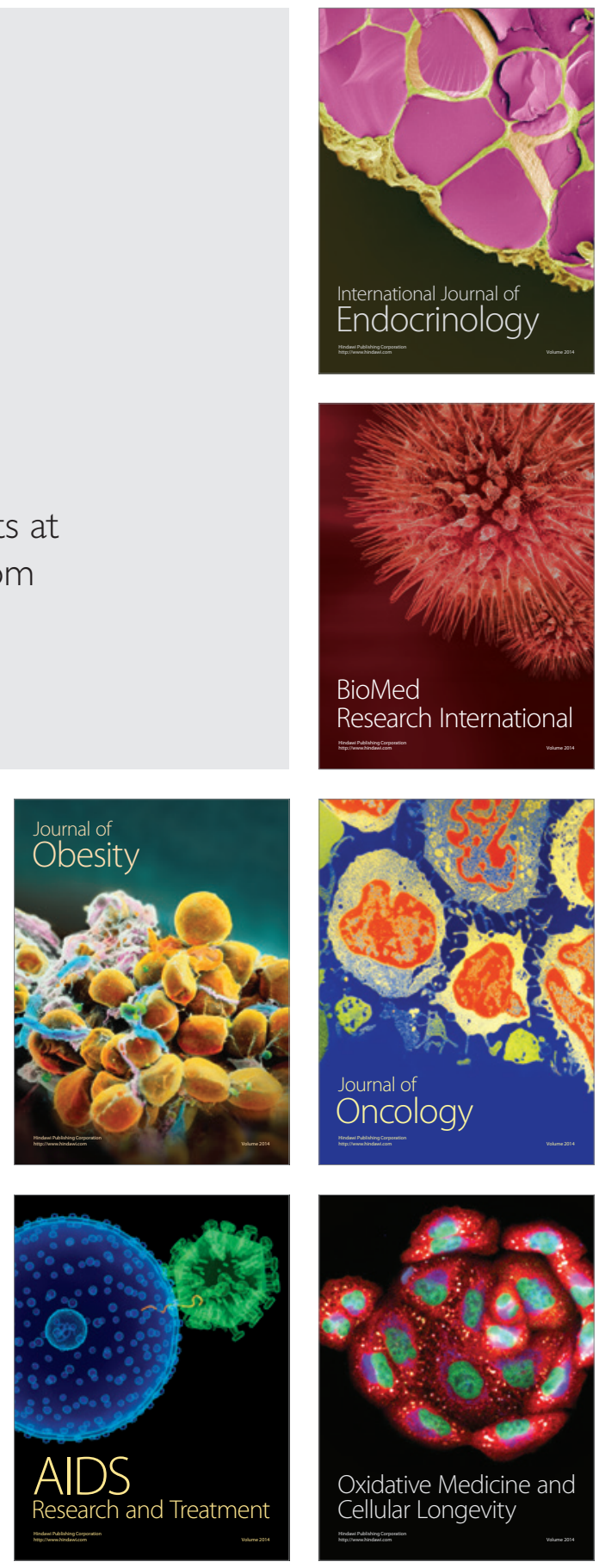